\title{
Perspectives on Inclusive Education with Reference to United Nations
}

\author{
Arvind Sharma \\ Faculty of Special Education, Dr. Shakuntala Misra National Rehabilitation University, India
}

Copyright $@$ ( 2015Horizon Research Publishing All rights reserved.

\begin{abstract}
This essay explores inclusive education and explains the role of United Nations for imparting it to different nations. Undoubtedly, the UN and the United Nations Children's Fund (UNICEF) strive for all children to have equitable access to education as a basic human right. The Convention on the Rights of the Child (CRC) combined with the Convention on the Rights of Persons with Disabilities (CRPD) form the heart of the international framework protecting children from education discrimination. While the UN system currently works towards achieving the EFA goals, it is also considering how to frame the post- 2015 agenda. The "Global Partnership on Children with Disabilities" (GPCWD) launched in 2012 as a network advocating for the rights of children with disabilities in the new agenda, including the mainstreaming or inclusion of disability rights across all global child-related agendas but the transition from current schools to inclusive education systems is not easy. Integration without systemic changes in organization, teaching techniques, and learning strategies can actually cause greater levels of exclusion as children with diverse needs are forced into an unaccommodating system but programme like United Nations Girls' Education Initiative (UNGEI) committed to supporting equal gender access to education and reducing the gender gap in both primary and secondary education.
\end{abstract}

Keywords UNICEF, Rights of Persons with Disabilities (CRPD), Education for All (EFA)

\section{Introduction}

There are more than one billion "persons with disabilities" in the world, $10 \%$ of whom are children mostly living in developing countries. Within the United Nations (UN) the term "disability" is defined as "any restriction or lack (resulting from an impairment) of ability to perform an activity in the manner or within the range considered normal for a human being." Negative societal attitudes founded on ignorance often cause children with disabilities to be perceived as different, dependent, and incapable, which leads to exclusion via marginalization, institutionalization, abandonment, or neglect. The magnitude of exclusion a child with disabilities faces depends not only on social attitudes, but also on contextual factors such as class, culture, location, disability type, and overall physical, political, and attitudinal barriers of their environment. Exclusion is also compounded by the frequent invisibility of children with disabilities as parents hide their children's disabilities to avoid ostracism or countries inadequately identify and assess children with disabilities. While the level and type of exclusion varies from child to child, the results are the same: children with disabilities are defined and judged by what they are missing rather than what they can offer.

The UN and the United Nations Children's Fund (UNICEF) strive for all children to have equitable access to education as a basic human right. Education is critical for children to develop their human capital and enhance their future economic and social opportunities. Children with disabilities are less likely than their peers to receive an education: roughly $90 \%$ of children with disabilities in developing countries do not attend school while the few who do often attend sub-par programs. "Equitable access" to education entails integrating children with disabilities into inclusive education systems rather than segregating and isolating children in separate institutions. These separate schools tend to offer inferior education, fail to address negative social perceptions that will impede a child's life outside of the classroom, and are too specialized to serve the broad spectrum of "disability." Since children with disabilities are a widely varied group encompassing physical, emotional, and mental disabilities, equitable access to education requires a variety of solutions.

\section{Origin of Inclusive Education}

The 'Salamanca Statement' adopted at the 'World Conference on Special Educational Needs: Access and Quality' called upon all governments and urged them to: Adopt as a matter of law or policy the principles of inclusive education, enrolling all children in regular schools, unless there are compelling reasons for doing otherwise [8]. 
There are two distinct perspectives on inclusive education. First, emerging largely from the developed countries, and the second, owing to the felt need and circumstances prevailing in the developing world. In richer developed countries, education is largely inclusive of girls, the disadvantaged and the ethnic groups. Children with disabilities physical and mental and learning difficulties, earlier getting education in separate special schools, are now being recommended to regular schools with inclusive orientation.

Therefore, the discourse on inclusive education in developed countries mostly centers on the extension of special education, or at most a reform in special education. The underlying approach in this perspective has been that children's disabilities are due to medical factors that need to be rectified in order to fit them in the organized school, its curriculum and pedagogy.

However, plethora of literature has emerged recently, which look at the inclusive education from educational reforms perspectives. Schools should respond to diverse needs of all children and fit themselves in children's learning styles and needs, and not the other way. Ainscow[1] have extensively dealt on the school reforms perspectives to develop the concept and practices of inclusive education. Continuing with this approach, Sebba and Ainscow[7] have offered a definition of inclusion: Inclusion describes the process by which a school attempts to respond to all pupils as individuals by reconsidering its curricular organization and provision. Through this process, the school builds its capacity to accept all pupils from the local community who wish to attend and, in so doing, reduces the need to exclude pupils.

The presumption in this definition is that most students from the local community would 'wish to attend' the neighborhood regular schools. Those who do not may be going either to special schools or the public (private) boarding schools. In the UK, on an average seven percent pupil attend private schools.

\section{Goal of Present Paper}

The present paper will describe the international frame work regarding inclusive education, explore UNCRPD with reference to United Nations organizations, identify barriers in imparting inclusive education and suggest few remedies.

\section{International Framework}

The Convention on the Rights of the Child (CRC) combined with the Convention on the Rights of Persons with Disabilities (CRPD) form the heart of the international framework protecting children from education discrimination. These documents build upon the pre-existing international framework for human rights, starting with the Charter of the United Nations, which commits Members States to support and uphold the work of the UN organs, including that of UNICEF. The Universal Declaration of Human Rights (UDHR) defines the common standards of basic rights people need to survive and live dignified lives. The UDHR and its six subsequent instruments create the remaining foundation of the CRC and CRPD.

The CRC builds on existing human rights conventions to fully articulate the rights of the child and provide guiding principles for protecting these rights. The CRC defines the basic civil, cultural, economic, political, and social rights of the child by setting health care, social services, and education standards. These outlined basic rights of all children are based on four core principles: non-discrimination; the right to life, survival, and development; dedication to the child's best interests; and respect for the child's view. The CPRD protects the equal treatment of people and children with disabilities and provides guidelines for changes Member States should make to rules, attitudes, and buildings to allow disabled children to have full and equitable access to schools and education. For example, schools cannot be segregated, all children must be able to articulate their needs to their teachers, and schools must provide reasonable accommodations and individualized support.

Several other international agreements form the foundation of protecting equitable access to education for children. The Convention against Discrimination in Education, which defines discrimination as- "any distinction, exclusion, limitation or preference which... has the purpose or effect of nullifying or impairing equality of treatment in education." It identifies what counts as discrimination in school, such as deprivation of access to any and all levels of education or limiting a person to inferior education options, and what does not. Separate but equal institutions for gender, religious, or linguistic reasons are acceptable per the Convention if they offer "equivalent access to education," hire teachers meeting the same standards of education, provide facilities of the same quality, and offer equivalent study courses as other institutions. The "Education for All" (EFA) initiative also contributes to the international framework concerning children with disabilities by seeking to provide all children, youth, and adults with quality basic education and was reaffirmed by the Dakar Framework for Action. The EFA initiative was launched at the World Conference on Education for All, after which the World Conference on Special Needs Education produced the Salamanca Declaration as a framework for action for regular schools to provide equitable access to education by accommodating the diverse needs of all children.

\section{Role of the United Nations System}

The EFA movement informs the work of all $\mathrm{UN}$ agencies providing education to children and is coordinated by UNICEF, the United Nations Educational, Scientific and Cultural Organization (UNESCO), the United Nations Development Programme (UNDP), the United Nations 
Population Fund (UNFPA), and the World Bank. EFA goals include the expansion of comprehensive early childhood education with an emphasis on access for the most disadvantaged and vulnerable children, ensuring universal access to free primary education for girls and children in difficult circumstances, and the achievement of gender equality in regards to education by 2015 . UNESCO leads the EFA coordination efforts since it is mandated to uphold every person's right to education; UNICEF's EFA contributions focus on childhood education per its mandate to "advocate for the protection of children's rights, to help meet their basic needs and to expand their opportunities to reach their full potential."

While the UN system currently works towards achieving the EFA goals, it is also considering how to frame the post2015 agenda. The "Global Partnership on Children with Disabilities" (GPCWD) launched in 2012 as a network advocating for the rights of children with disabilities in the new agenda, including the mainstreaming or inclusion of disability rights across all global child-related agendas. Coordinated by UNICEF, its partners include over international, national, and local non-governmental organizations (NGOs); governments; Disabled People's Organizations (DPOs); academics; and private sector actors. One of GPCWD's four task forces is the Task Force on Inclusive Education led by UNICEF and UNESCO. Its first year action plan includes promoting inclusive and accessible learning spaces through the use of existing funding, investing in training teachers for disability-inclusive education, and improving data collection to monitor progress and build evidence.

\section{Barriers to Equitable Education for Children with Disabilities}

Equitable education encompasses two dimensions: fairness or guaranteeing no personal or social circumstance inhibits education access, and inclusion, or ensuring all students have access to the same standard of education. A large variety of factors inhibit equitable access to education. Policy and systemic factors include discriminatory policy that segregates students or a lack of any policy that addresses students with disabilities, limited resources to enact policy, or limited training for teachers. Social factors include negative social and parental attitudes concerning disabilities, sometimes due to religious or cultural views of disabilities as punishments. School factors include inadequate teacher training in inclusive methodology and a lack of funding leading to inappropriate and inaccessible facilities, high student-teacher ratios, and too little support for students with disabilities. Addressing all of these factors hinges on addressing several specific barriers to equitable education for children with disabilities.

\section{Identifying Children with Disabilities}

The identification of children with disabilities varies from country to country and can be as limited as recognizing the four "traditional" categories of blindness, deafness, physical disabilities, and mental retardation. More complex identifiers such as the International Classification of Function, Disability and Health (ICF) can include children with learning disabilities or socioeconomic disadvantages resulting in underperformance in school. Sponsored by World Health Organization (WHO), the ICF examines disability as a construct of an individual interacting with his or her environment instead of an innate deficiency. The ICF mainstreams the concept of disability from a minority to a universal human experience by considering how all people can experience health deficiencies that cause some degree of disability, thus discouraging negative social attitudes about a minority demographic. Children are even more difficult to classify due to childhood development factors and variations in development speeds. The subsequent International Classification of Function, Disability and Health for Children and Youth (ICH-CY) takes the mainstream perspective of disabilities and applies it to children in an attempt to provide standard measures in line with childhood development factors. These added dimensions envelop body structures, body functions, limitations on activity, and restrictions of participation.

\section{Visibility and Data Collection}

As UNICEF reports in The State of the World's Children 2013, "A society cannot be equitable unless all children are included, and children with disabilities cannot be included unless sound data collection and analysis render them visible." Disability data strengthens the capacity of UNICEF to screen and identify children with disabilities, thus increasing visibility and making it more possible for such children to reach health and social services, including education. It also enables UNICEF to assess its work and track progress made towards international goals established in the CRC and CRDP as well as program-specific benchmarks. Such monitoring and refinement requires the analysis of data concerning enrolment, attendance, completion, and dropout rates for children with disabilities as well as the significance of constants like gender, ethnicity, geographical location, and income level.

UNICEF is working with the Washington Group on Disability Statistics, housed within the United States Centers for Disease Control and Prevention, to improve data collection methodology. The partnership is developing a screening tool for determining whether or not children have disabilities based on the ICH-CY by focusing on activity limitations and the social exclusion context of child disabilities. The hope is that this tool will make it more likely for states to use a more comprehensive definition of "disability"; the tool should also develop standard overall methodology when conducting in-depth assessments of disability in children and plans for future implementation of 
a teach toolkit to increase data collection. Improved data, according to research conducted by UNICEF and UNESCO's joint "Global Initiative on Out-of-School Children," is crucial to identify why funded policies and programs designed to increase access to education for all children have been unsuccessful. While the Initiative notes disability as a structural challenge for inclusion, the data does not specifically address the demographic.

\section{Compounded Gender Challenges: Girls, Disabilities, and Education}

Gender compounds the disadvantages of disabled girls, causing them to be "doubly disabled." They are more likely than disabled boys or girls without disabilities to receive an education, continue into vocational training, or find employment. For example, a 2011 World Health Organization (WHO) report found that $50.6 \%$ of males with disabilities completed primary school while only $41.7 \%$ of girls with disabilities did. Girls with disabilities also face challenges unique to their gender, such as lacking privacy at school when using the toilet or changing clothes. In terms of security and safety, they are more vulnerable to sexual and physical abuse at home, at school, or on the way to school. Girls with disabilities are also more likely to be domestically exploited than girls without disabilities, as parents can perceive education to be less useful for the former group. The post-2015 development agenda needs to consider the compounding effects of gender and disabilities. UNICEF co-leads the GPCWD Task Force on Inclusive Education, which, though in its preliminary agenda-setting phase, has made equitable access to education for girls with disabilities a priority for its first year.

\section{Creating Inclusive Education Systems}

Equitable access to education requires inclusive education to ensure that all students have access to the same standard of education. Education systems can be categorized into three levels of access for children with disabilities: segregated education where certain groups of children are educated at home or in special schools, integrated education, and inclusive education. Sharma, A.[6] reported that Integrated education mainstreams children with disabilities into school by creating special accommodating classes, while inclusive education restructures the entire school culture, including policies and practices, to meet the needs of all students. The concept of inclusive education holds that while children have different characteristics, abilities, and needs, they should be able to learn together in an environment that does not establish differences between individual children but rather views integration as opportunities for change and enriched learning. This paradigm has been promoted by the recent convergence between the movements for human rights and rights for people with disabilities. The following sections describe several changes required to create inclusive education systems.

\section{Physical Accommodations \& Assistive Technology}

Children with disabilities require a variety of physical accommodations to be fully integrated into the education system. These accommodations include access to tools like sign language and Braille integrated into fully adaptive curricula and physical accommodations like ramps and wide doorways. Assistive Technology (AT) broadly categorizes the physical tools that support children with disabilities. Assistive Technology devices range widely and include access and environmental controls like electronic controls or Braille signs, listening aids like captions and hearing aids, alternative/augmentative communication like picture boards and communication software, computer-based instruction, and visual aids like books on tape and Braillers. The UNICEF-coordinated Assistive Technology Task Force Plan of Action includes the identification of a variety of inclusion-enhancing open source ATs to be tested for implantation and possible scale up. As of 2013, the plan does not have an implementation date and remains on the agenda for discussion. Policy experts have suggested AT investments such as a UNICEF- sponsored scale-up consider whole-life costs including purchase price and upkeep. Investment should then begin with low-cost devices like reading stands, white canes, pencil grips, and sign language before moving to medium- cost options (hearing aids or Braille materials) and high-cost computer-based technology.

Systemic Policy Shifts Inclusive education requires not only the integration of children with disabilities into the classroom but also restructuring the culture, practices, and policies of schools, such as that children with disabilities are not viewed as minorities nor put into separate and unequal special education classes. The first of three policy shifts is implementing changes in the overall education system to avoid segregation and sorting students into different groups based on abilities. Secondly, fair and inclusive practices must be designed to identify those struggling within the curriculum and provide systematic help to reduce school-year repetition rates, such as classroom interventions including reading recovery strategies and formative assessment. Schools should also assist disadvantaged parents with helping their children to learn and thus strengthen the connection between home and school, and provide for successful inclusion of minorities, including children with disabilities, within mainstream education. Finally, allocation and use of resourcing must also be fair and inclusive, including by prioritizing early childhood education for all demographics and directing more resources to students with the greatest needs.

The transition from current schools to inclusive education systems is not easy. Integration without systemic changes in organization, teaching techniques, and learning strategies 
can actually cause greater levels of exclusion as children with diverse needs are forced into an unaccommodating system. Barriers to this transition include negative social attitudes, limited resources, and lack of focus on the particular needs of girls with disabilities. UNICEF supports schools making this transition through efforts like the United Nations Girls' Education Initiative (UNGEI), an EFA flagship initiative committed to supporting equal gender access to education and reducing the gender gap in both primary and secondary education.

\section{Teacher Training and Support for Inclusive Education}

Mittler \& Norwich $[4,5]$ found that inadequate teacher training and knowledge is a significant barrier to the transition to fully inclusive classrooms. Such training should include mainstreaming special needs education across training courses and developing targeted training. Systematic changes in pre-service and in-service training should address methodologies of collaborative teaching and differentiated instruction, where the same content can be taught with varying teaching methods in response to different learning styles and levels throughout the classroom. These strategies have been found to effectively meet all children's diverse needs. UNICEF recommends that teacher-training curricula should also include child-centered methodology, teaching techniques in multicultural and inclusive environments, and how to support children with disabilities and specific educational needs with adaptable individual education plans. Furthermore, training should embody an understanding of human rights, in particular, the right of non- discrimination, and teach how to understand, recognize, and positively address both indirect and direct discrimination in schools in order to create a more inclusive school culture.

Inclusive education systems must also provide sufficient support for teachers within schools, including a senior dedicated staffer that ensures inclusive practices and acts as a resource for other teachers, realistic and appropriate staffing levels, leadership and support from the school's governors, joint problem solving and co-teaching among the staff, and utilizing students' families and communities as resources. Schools that cannot afford to fully retrain teaching staff could alternatively train one teacher per facility to become the touchstone for learning support for the wider staff. Curriculum and teaching practices can also utilize classroom assistants who can support children with disabilities as they learn and access building facilities. This alternative to new construction offers a viable alternative for inclusive education when schools cannot afford large systemic overhauls, plus it integrates members of the community into the classroom and can offer positive roles to parents of children with disabilities.

\section{Conclusions}

Children with disabilities face significant barriers to equal access to education. UNICEF works to establish equitable education systems to help equalize the ability of children both with and without disabilities to access the same quality of education. Progress towards this goal is difficult to measure due to the invisibility of disabled children, a lack of data, and a lack of uniform definitions and collection methodologies. Even with the limited data available, it is clear that girl children with disabilities have an even lower rate of access to education than boy children with disabilities due to the added effects of the gender gap in education. While several challenges have been identified, past work has also identified ways to move forward and increase equitable access.

While equitable education strives to be fair by serving all demographics equally, it also requires the establishment of inclusive education systems. This requires a complete system shift in education policy and the retraining of teachers in accordance with the new approach. School facilities must make physical adaptations to support the interaction of students with disabilities, primarily through the use of AT. UNICEF has identified equitable access to education for children with disabilities as an important agenda item moving into the post-2015 agenda. As a relatively new focus, the topic provides many opportunities for new action and policy.

\section{REFERENCES}

[1] Ainscow, M. (2005) From Special Education to Effective Schools for All, Keynote presentation at the Inclusive and Supportive Education Congress 2005, University of Strathclyde, Glasgow

[2] Government of India and UN Systems. Perspectives in Special Needs Education in India: A Journey from Isolation to Inclusion. Community Based Primary Education: Janshala, Monthly Newsletter, Jan- March, 2003 (On-Line), Available: http://www.un.org.in/JANSHALA

[3] Kelly, E. (2004). Human rights as foreign policy imperatives. In D.K. Chatterjee (Ed.): The ethics of assistance. Morality and the distant needy. UK: Cambridge University Press.

[4] Mittler, P. (2000). Working Towards Inclusive Education Social Contexts. London: David Fulton Publishers.

[5] Norwich, B. (2002). Education, inclusion and individual differences: Recognizing and resolving dilemmas, British Journal of Educational Studies, London.

[6] Sharma, Arvind (2014). Inclusive Education: A gateway to inclusive society. InGupta, Madhu. (ed.): Inclusive Education: Issues \& Challenges, Mastermind Publications, Meerut (UP).

[7] Sebba, T. \& Aniscow, M. (1996). Effective Schools for All, London: David Fulton Publishers

[8] UNESCO (1994). The Salamanca statement and framework for action on special needs education. Paris: UNESCO.

[9] UNESCO (2005). Review of the Present Situation in Special Needs Education, Paris. 